\title{
Diffusion-weighted imaging as predictor of acute ischemic stroke etiology
}

\author{
Imágenes por difusión cerebral como predictor de la etiología del accidente \\ cerebrovascular isquémico agudo
}

\author{
Alejandro Michel BRUNSER ${ }^{1,2,3}$, Eloy MANSILLA ${ }^{1,3}$, Victor NAVIA ${ }^{1,3}$, Enrico MAZZON ${ }^{1,3,4}$, Alexis ROJO5, \\ Gabriel CAVADA ${ }^{6}$, Verónica OLAVARRIA ${ }^{1,3,4}$, Paula Muñoz VENTURELLI1,3,7, Pablo Manuel. LAVADOS ${ }^{1,3}$
}

\begin{abstract}
Background:Topographic patterns may correlate with causes of ischemic stroke. Objective: To investigate the association between diffusionweighted imaging (DWI) and Trial of Org 10172 in Acute Stroke Treatment (TOAST) classification. Methods: We included 1019 ischemic stroke patients. DWI were classified as: i) negative; ii) DWI single lesion (cortico-subcortical, cortical, subcortical $\geq 20 \mathrm{~mm}$, or subcortical $<20 \mathrm{~mm}$ ); iii) scattered lesions in one territory (small scattered lesions or confluent with additional lesions); and iv) multiple lesions (multiple unilateral anterior circulation [MAC], multiple posterior circulation [MPC], multiple bilateral anterior circulation [MBAC], and multiple anterior and posterior circulations [MAP]). Results: There was a relationship between DWI patterns and TOAST classification ( $p<0.001)$. Large artery atherosclerosis was associated with small, scattered lesions in one vascular territory (Odds Ratio [OR] 4.22, 95\% confidence interval [95\% Cl] 2.61-6.8), MPC (OR 3.52; 95\% Cl 1.54-8.03), and subcortical lesions $<20 \mathrm{~mm}$ (OR 3.47; 95\% Cl 1.76-6.85). Cardioembolic strokes correlated with MAP (OR 4.3; 95\%Cl 1.64-11.2), cortico-subcortical lesions (OR 3.24; 95\%Cl 1.9-5.5) and negative DWI (OR 2.46; $95 \% \mathrm{Cl} 1.1-5.49)$. Cryptogenic strokes correlated with negative DWI (OR 4.1; 95\% Cl 1,84-8.69), cortical strokes (OR 3.3; 95\% Cl 1.25-8.8), MAP (OR 3.33; 95\% Cl 1.25-8.81) and subcortical lesion $\geq 20 \mathrm{~mm}$ (OR 2.44; 95\% Cl 1,04-5.73). Lacunar strokes correlated with subcortical lesions diameter 20 mm (OR 42.9; 95\%Cl 22.7-81.1) and negative DWI (OR 8.87; 95\%Cl 4.03-19.5). Finally, MBAC (OR 9.25; 95\%Cl 1.12-76.2), MAP (OR 5.54; 95\% Cl 1.94-15.1), and MPC (OR 3.61; 95\% Cl 1.5-8.7) correlated with stroke of other etiologies. Conclusions: A relationship exists between DWI and stroke subtype.
\end{abstract}

Keywords: Stroke; Ischemic Stroke; Diffusion Magnetic Resonance Imaging; Diagnosis.

\section{RESUMEN}

Antecedentes: Los patrones topográficos pueden correlacionarse con las causas del accidente cerebrovascular isquémico. Objetivo: Investigar la asociación entre imágenes ponderadas por difusión por resonancia nuclear magnética (dRNM) y el ensayo de Org 10172 en la clasificación de tratamiento agudo de accidentes cerebrovasculares (TOAST). Métodos: Fueron incluidos 1.019 pacientes con accidente cerebrovascular isquémico. Las dRNM fueron clasificadas como: i) negativa; ii) dRNM lesión única (cortico-subcortical, cortical, subcortical $\geq 20 \mathrm{~mm}$, o subcortical $<20 \mathrm{~mm}$ ); iii) lesiones disgregadas un territorio vascular (pequeñas lesiones dispersas o confluentes con lesiones adicionales); y iv) lesiones múltiples (unilaterales de circulación anterior [MAC], de circulación posterior [MPC], bilaterales de circulación anterior [MBAC] y de circulación anterior y posterior [MAP]). Resultados: Existió relación entre los patrones de dRNM y la

\footnotetext{
${ }^{1}$ Clínica Alemana de Santiago, Department of Neurology and Psychiatry, Vascular Neurology Service, Neurology Unit, Santiago, Chile.

${ }^{2}$ Clínica Alemana de Santiago, Emergency Department, Vascular Neurology Service, Neurology Unit, Santiago, Chile.

${ }^{3}$ Universidad del Desarrollo, Facultad de Medicina Clínica Alemana, Santiago, Chile.

${ }^{4}$ Clínica Alemana de Santiago, Department of Critical Care, Santiago, Chile.

${ }^{5}$ Hospital Clínico Herminda Martin de Chillán, Servicio de Salud Nuble, Servicio de Neurología, Chillán, Chile.

${ }^{6}$ Clínica Alemana de Santiago, Unidad de Investigación y Ensayos Clínicos, Departamento de Desarrollo Acedémico e Investigación, Santiago, Chile.

־Universidad del Desarrollo, Facultad de Medicina Clínica Alemana Santiago, Instituto de Ciencias e Innovación en Medicina, Centro de Estudios Clínicos, Santiago, Chile.

AMB (D) https://orcid.org/0000-0002-8376-9450; EMansilla (iD) https://orcid.org/0000-0002-0326-930X; VN (ID https://orcid.org/0000-0002-5920-7730; EMazzon (D) https://orcid.org/0000-0001-7662-8556;AR (D) https://orcid.org/0000-0002-7937-8713; GC (D) https://orcid.org/0000-0002-3558-0266; VO (iD https://orcid.org/0000-0003-4300-9921; PMV (D) https://orcid.org/0000-0003-1869-2255; PML (D) https://orcid.org/0000-0002-9118-9093 Correspondence: Alejandro Michel Brunser; Email: abrunser2017@gmail.com.

Conflict of interest: Alejandro Brunser, Eloy Mansilla, Victor Navia, Enrico Mazzon, Alexis Rojo, Gabriel Cavada: reports no conflicts of interest; Verónica Olavarría: research grants from Clínica Alemana de Santiago, Boehringer Ingelheim and CONICYT outside of the study; Paula Muñoz Venturelli: reports research grants from The George Institute, Clínica Alemana de Santiago and CONICYT outside of the study; Pablo M. Lavados: reports research grants from The George Institute and Clínica Alemana de Santiago during the conduct of the study;ANGELs advisory board. Unrestricted research grant from Boehringer Ingelheim.
}

Authors' contributions: AB, PL, VO, PM, E Mansilla: conception and design; AB, EMazzon, AR, VN, EMansilla: acquisition of data; AB, GC: analysis and interpretation of data; AB, PL, VO, PM: drafting the article; EMansilla, AR, GC, AR, EMazzon, VN: approval of the version.

Received on March 06, 2021; Received in its final form on May 05, 2021; Accepted on May 10, 2021. 
clasificación TOAST ( $p<0,001)$. La aterosclerosis de las arterias grandes se asoció con lesiones pequeñas y disgregadas en un territorio vascular (Odds Ratio [OR] 4,22, intervalo de confianza del 95\% [IC95\%] 2,61-6,8), MPC (OR 3,52; IC95\% 1,54-8,03), y lesiones subcorticales <20 mm (OR 3,47; IC95\% 1,76-6,85). Cardioembolias se relacionaron con MAP (OR 4,3; IC95\% 1,64-11,2), lesiones cortico-subcorticales (OR 3,24; IC95\% 1,9-5,5) y dRNM negativas (OR 2,46; IC95\% 1,1-5,49). Los accidentes cerebrovasculares criptogénicos se relacionaron con dRNM negativas (OR 4,1; IC95\% 1,84-8,69), accidentes cerebrovasculares corticales (OR 3,3; IC95\% 1,25-8,8), MAP (OR 3,33; IC95\% 1,258,81 ) y lesiones subcorticales $\geq 20 \mathrm{~mm}$ (OR 2,44; IC95\% 1,04-5,73). Los accidentes cerebrovasculares lacunares se correlacionaron con lesiones subcorticales de diámetro 20 mm (OR 42,9; IC95\% 22,7-81,1) y dRNM negativas (OR 8,87; IC95\% 4,03-19,5). Finalmente, MBAC (OR 9,25; IC95\% 1,12-76,2), MAP (OR 5,54; IC95\% 1,94-15,1) y MPC (OR 3,61; IC95\% 1,5-8,7) se relacionaron con accidentes cerebrovasculares de otras etiologías. Conclusiones: Existe relación entre dRNM y subtipo de accidente cerebrovascular.

Palabras clave: Accidente Cerebrovascular; Accidente Cerebrovascular Isquémico; Imagen de Difusión por Resonancia Magnética; Diagnóstico.

\section{INTRODUCTION}

A precise and early diagnosis of acute ischemic stroke (AIS) etiologic subtype is important for therapeutic decisions that may influence stroke recurrence, management, and prognosis ${ }^{1,2}$. The most frequently used method for causative subtype classification is the Trial of Org 10172 in Acute Stroke Treatment (TOAST), which divides AIS into subtypes, based primarily on infarction mechanism ${ }^{1,2}$.

Diffusion-weighted imaging (DWI) is sensitive and specific for the early detection of hyper-acute ischemic lesions, even those of very small size ${ }^{3-5}$. Ischemic lesion topography on DWI may correlate with stroke subtypes. However, previous studies demonstrating this association were limited to specific stroke etiologies or DWI patterns, included transient ischemic attacks, were retrospective, included AIS of the anterior circulation only, or did not consider negative DWI results ${ }^{5-13}$, which could represent a proportion as high as $13 \%$ of the AIS admitted to the emergency room $(\mathrm{ER})^{4}$.

In this study we aimed to determine the association between DWI ischemic topography and AIS stroke subtype using the causative TOAST classification. A large prospective cohort of consecutive, unselected patients with AIS admitted to out center was evaluated.

\section{METHODS}

In this prospective study, patients with AIS admitted to the ER between December 2012 and June 2019 were evaluated by the neurologist on call. Age, stroke risk factors, and time from stroke onset to arrival to the ER, defined as the last time at which the patient was known to be free of any neurological deficits, were recorded. Stroke severity was assessed with the National Institutes of Health Stroke Scale (NIHSS). Patients were then studied with the local neuroimaging protocol, which has been described previously ${ }^{4}$. The protocol consists of a non-contrast brain computed tomography (NCCT) and, in patients without contraindication, an immediate spiral computed tomographic angiography to evaluate the cervical and intracranial arteries (CTA) and DWI-MRI. If a CTA could not be obtained, an acute magnetic resonance angiography (AngioMR) was performed.

The time from symptom onset to the time when the DWI was performed was recorded, as well as the model of the MRI equipment in which this study was carried out. Evaluations were performed either in a GE HdxT 1.5-T MRI or in a Siemens Skyra 3-Tesla and varied according to their availability upon arrival. A standardized protocol was applied including axial acquisitions and, in patients with negative results, thin coronal sections were also performed ${ }^{4}$.

After the initial evaluation, most patients were transferred to the Stroke Unit for at least a 48-hour follow up. Telemetry monitoring was performed in all cases, and as soon as possible cardiologists carried out a transthoracic echocardiogram. Additional evaluations were performed as required to determine infrequent causes of AIS.

Patients with negative baseline DWI results in the ER were re-evaluated after 24 hours with either brain NCCT or MRI according to the preference of the attending neurologist.

Patients with repeated negative imaging, but with an evident neurovascular syndrome, and no other alternative diagnosis explaining the patient's initial symptoms after extensive workup were finally diagnosed as stroke ${ }^{3}$.

DWI topography of the ischemic lesions was determined by an experienced stroke neurologist $(\mathrm{AB})$, based on a modification of a previous classification ${ }^{10}$. In this article, we included negative baseline DWI results as a variable and we changed the subgroup criteria for single subcortical lesions from $15 \mathrm{~mm}$ to $20 \mathrm{~mm}$. Ischemic baseline patterns were classified as follows: i) absence of acute lesion or normal baseline DWI; ii) single lesions group (which includes as subgroups cortico-subcortical lesion, pure cortical lesion, subcortical lesion with a diameter $\geq 20 \mathrm{~mm}$ or subcortical lesions with a 
diameter <20 mm) (Figure 1); iii) scattered lesions of less than $15 \mathrm{~mm}$ in one vascular territory (SLVT) and scattered and confluent lesions of $15 \mathrm{~mm}$ or more (Figure 2); and iv) multiple lesions in multiple vascular territories (unilateral anterior circulation [MAC], posterior circulation [MPC], bilateral anterior circulation [MBAC], or both anterior and posterior circulation [MAP]) (Figure 3).

The reviewer was blinded to the clinical data of patients; the etiological stroke classification was made at the time of discharge by the treating neurologist, and according to the TOAST classification ${ }^{2}$.

The Ethics Committee of Universidad del Desarrollo, Clínica Alemana de Santiago approved the protocol, and the patients or their relatives provided written informed consent as part of the local prospective stroke registry.

\section{Statistical analysis}

DWI patterns and their association with stroke etiology were described in an analysis of simple correspondence to identify closeness between the pattern and the etiology. The significance of this proximity was evaluated with Fisher's exact test. The strength of the association was calculated as Odds Ratio (OR) with a level of significance of $5 \%$ and $95 \%$ confidence interval (95\%CI).

The significant associations are shown in a bi-plot obtained through a simple correspondence analysis.

Data were processed with the Stata v 14.0 software.

\section{RESULTS}

During the study period, 1108 consecutive AIS patients were admitted to the ER; 1019 (91.9\%) were included in this analysis. Eighty-nine patients were excluded because of a contraindication for MRI (peacemaker, agitation, critical medical condition, or low quality of the DWI image).

Mean patient age was $72.5 \pm 17.4$ years and $562(55.5 \%)$ patients were women. Mean NIHSS was $3 \pm 7.1$. Mean time from stroke onset to ER arrival was $322 \pm 1786$ minutes and mean time from AIS onset to DWI was $376 \pm 1803$ minutes. In relation to time to imaging, 450 (44.2\%) patients were assessed with DWI within 4.5 hours of symptom onset and in 824 (80.9\%) DWI was performed within the first 24 hours; 97 cases $(9.5 \%)$ were evaluated between 24 and 48 hours and only 98 (9.6\%) patients were assessed with DWI more than 48 hours after symptom onset. A 3T MRI was used in 193 (18.9\%) of the cases, and $308(30.2 \%)$ patients were treated with intravenous thrombolysis.

Ischemic lesion patterns in baseline DWI by the TOAST classification are described in Table 1. No lesion was found in baseline DWI evaluation of 142 patients (14\%); a single lesion was observed in 483 patients $(47.3 \%)$, scattered lesions in one vascular territory were observed in 198 cases (19.4\%). Finally, multiple lesions in multiple vascular territories were found in 196 patients $(19.3 \%)$.

The assessment of the association between baseline DWI patterns and AIS TOAST subgroups is shown in Figure 4 and Table 2. Large artery atherosclerosis (LAA) was associated with small scattered lesions in one vascular territory

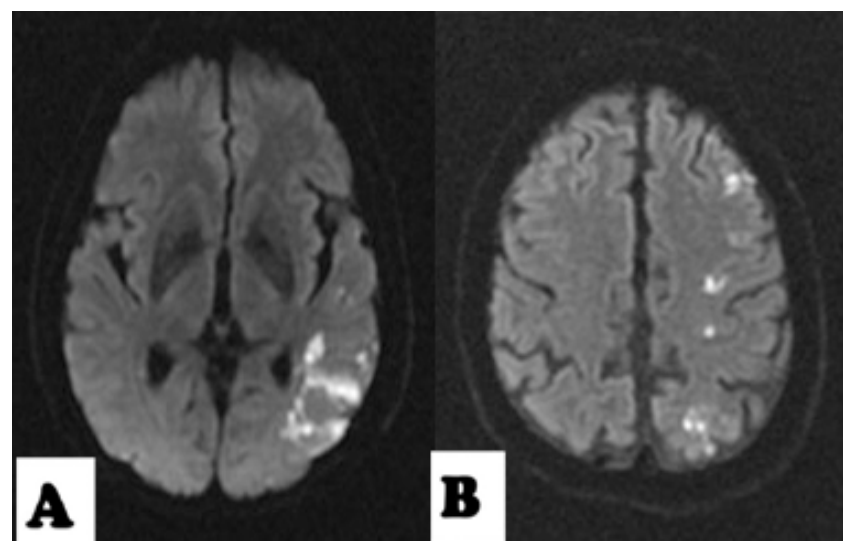

Figure 2. Scattered lesions in one vascular territory. A: scattered lesions or confluent lesions greater than $15 \mathrm{~mm}$ with an additional lesion. B: Scattered lesions in one vascular territory. A: small ones, less than $15 \mathrm{~mm}$.

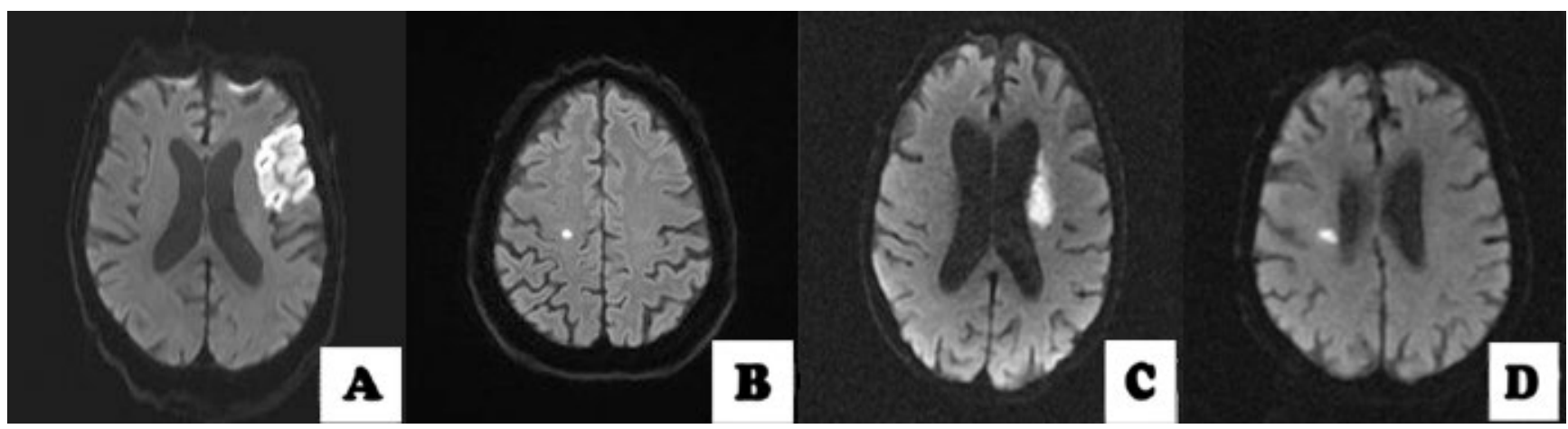

Figure 1. (A) cortico-subcortical lesion; (B): pure cortical lesion; (C) subcortical lesion with a diameter $\geq 20$ mm; (D) subcortical lesion with a diameter $<20 \mathrm{~mm}$. 


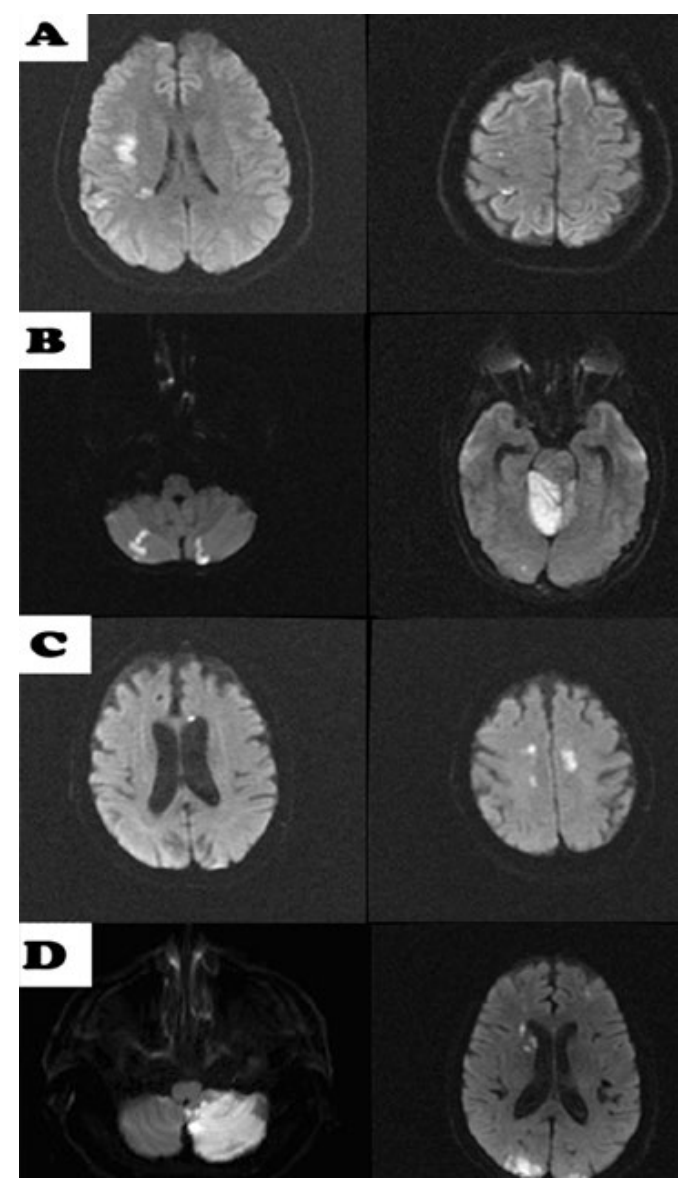

Figure 3. Multiple lesions in multiple vascular territories. (A) unilateral anterior circulation; (B) posterior circulation; (C) bilateral anterior circulations; (D) anterior and posterior circulations.

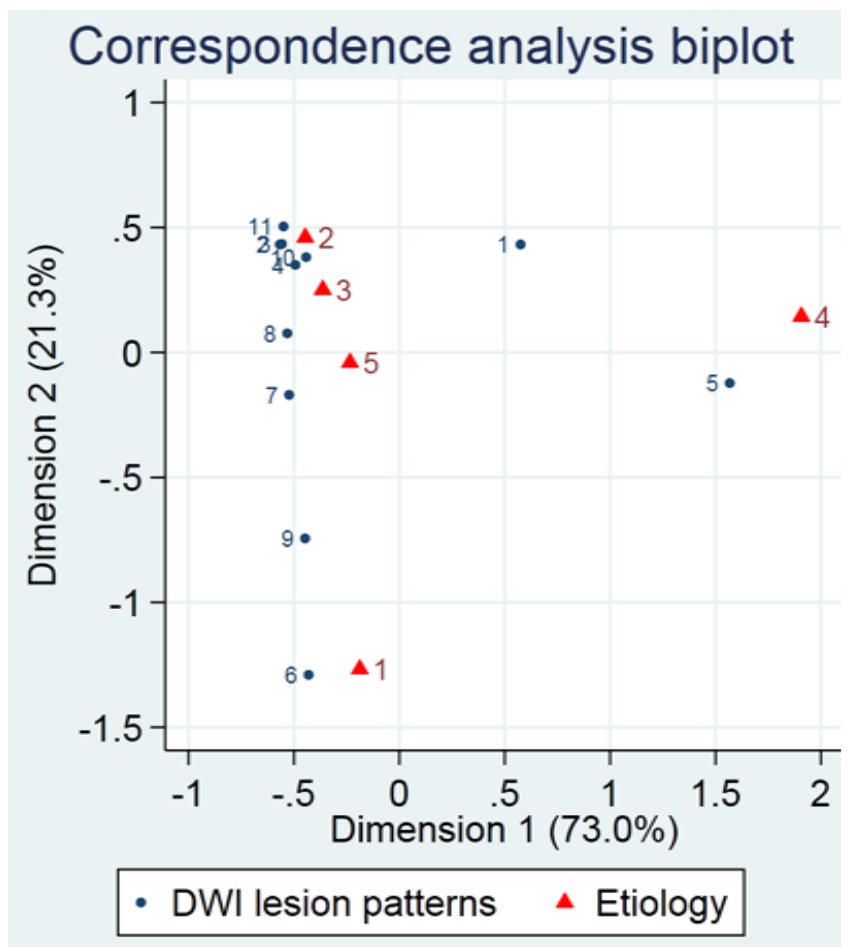

Red Triangle - 1: large-artery atherosclerosis, 2: cardioembolic, 3: cryptogenic, 4: lacunar disease, 5: other causes. Blue dots - 1: negative DWI, 2: corticosubcortical lesion, 3: pure cortical stroke, 4: subcortical lesion with a diameter $\geq 20 \mathrm{~mm}$, 5: subcortical lesion with a diameter $<20 \mathrm{~mm}, 6$ : scattered lesions in 1 vascular territory (small ones, less than $15 \mathrm{~mm}$ ), 7: scattered lesions in 1 vascular territory or confluent $>15 \mathrm{~mm}$ lesions with an additional lesion, 8: multiple lesions (ML) in the unilateral anterior circulation, 9: $\mathrm{ML}$ in the posterior circulation, 10: ML in bilateral anterior circulation, 11: ML in anterior and posterior circulations.

Figure 4. Correspondence analysis biplot between diffusionweighted imaging lesions patterns and etiology by Trial of Org 10172 in Acute Stroke Treatment posterior circulations.

Table 1. Ischemic lesion patterns at baseline diffusion-weighted imaging by Trial of Org 10172 in Acute Stroke Treatment classification.

\begin{tabular}{|c|c|c|c|c|c|c|}
\hline DWI pattern/TOAST subtypes & $\begin{array}{c}\text { LAA } \\
(n=173)\end{array}$ & $\begin{array}{l}\text { Cardioembolic } \\
\qquad(n=282)\end{array}$ & $\begin{array}{l}\text { Cryptogenic } \\
\quad(n=289)\end{array}$ & $\begin{array}{l}\text { Lacunar } \\
(n=153)\end{array}$ & $\begin{array}{l}\text { Other causes } \\
\qquad(n=122)\end{array}$ & $\begin{array}{c}\text { Total } \\
(n=1,019)\end{array}$ \\
\hline Negative DWI & 8 & 30 & 47 & 46 & 11 & 142 \\
\hline Single lesion & & & & & & 483 \\
\hline Corticosub-cortical & 20 & 84 & 61 & 0 & 18 & 183 \\
\hline Cortical & 5 & 18 & 26 & 0 & 5 & 54 \\
\hline Subcortical $20 \mathrm{~mm}$ and over & 7 & 24 & 27 & 1 & 11 & 70 \\
\hline Subcortical less $20 \mathrm{~mm}$ & 26 & 16 & 14 & 105 & 15 & 176 \\
\hline SLVT & & & & & & 198 \\
\hline SLVT Small (<15 mm) & 61 & 22 & 33 & 0 & 15 & 131 \\
\hline SLVT Confluent lesion ( $\geq 15 \mathrm{~mm}$ ) & 16 & 25 & 20 & 0 & 6 & 67 \\
\hline Multiple lesions & & & & & & 196 \\
\hline MAC & 4 & 10 & 5 & 0 & 4 & 23 \\
\hline MPC & 18 & 9 & 17 & 0 & 13 & 57 \\
\hline MBAC & 3 & 12 & 13 & 1 & 7 & 36 \\
\hline MAP & 5 & 32 & 26 & 0 & 17 & 80 \\
\hline
\end{tabular}

DWI: diffusion-weighted imaging; LAA: large-artery atherosclerosis; SLVT: scattered lesions in one vascular territory; MAC: multiple lesions in unilateral anterior circulation; MPC: multiple lesions in posterior circulation; MBAC: multiple lesions in the bilateral anterior circulation; MAP: multiple lesions anterior and posterior circulations. 
Table 2. Associations between diffusion-weighted imaging patterns and Trial of Org 10172 in Acute Stroke Treatment subgroups.

\begin{tabular}{|c|c|c|c|c|}
\hline DWI pattern & Etiology & OR & $p$-value & $95 \% \mathrm{Cl}$ \\
\hline \multirow{5}{*}{ Negative } & LAA & 1.00 & & \\
\hline & LC & 8.87 & $<0.001$ & $4.03-19.52$ \\
\hline & Undet & 4.01 & $<0.001$ & $1.84-8.7$ \\
\hline & CE & 2.46 & 0.029 & $1.1-5.49$ \\
\hline & Other & 2.04 & 0.13 & $0.80-5.24$ \\
\hline \multirow{5}{*}{$\begin{array}{l}\text { Cortico- } \\
\text { subcortical }\end{array}$} & LAA & 1.00 & & \\
\hline & CE & 3.24 & $<0.001$ & $1.9-5.52$ \\
\hline & Undet & 2.1 & 0.01 & $1.18-3.52$ \\
\hline & Other & 1.32 & 0.42 & $0.66-2.62$ \\
\hline & LC & Empty & & \\
\hline \multirow{5}{*}{ Cortical } & LAA & 1.00 & & \\
\hline & Undet & 3.32 & 0.016 & $1.25-8.81$ \\
\hline & CE & 2.29 & 0.18 & $0.83-6.28$ \\
\hline & Other & 1.43 & 0.57 & $0.4-5.07$ \\
\hline & LC & Empty & & \\
\hline \multirow{5}{*}{$\begin{array}{l}\text { Subcortical } \\
>20 \mathrm{~mm}\end{array}$} & LAA & 1.00 & & \\
\hline & Undet & 2.44 & 0.04 & $1.04-7.73$ \\
\hline & Other & 2.35 & 0.08 & $0.88-6.24$ \\
\hline & CE & 2.2 & 0.07 & $0.92-5.23$ \\
\hline & LC & 0.15 & 0.08 & $0.01-1.28$ \\
\hline \multirow{5}{*}{$\begin{array}{l}\text { Subcortical } \\
<20 \mathrm{~mm}\end{array}$} & Undet & 1.00 & 1.00 & \\
\hline & LC & 42.9 & $<0.001$ & $22.7-81.1$ \\
\hline & LAA & 3.47 & $<0.001$ & $1.76-6.85$ \\
\hline & Other & 2.75 & 0.009 & $1.28-5.89$ \\
\hline & CE & 1.18 & 0.65 & $0.56-2.46$ \\
\hline \multirow{5}{*}{ SSCL } & Undet & 1.00 & & \\
\hline & LAA & 4.22 & $<0.001$ & $2.61-6.8$ \\
\hline & Other & 1.08 & 0.145 & $0.56-2.08$ \\
\hline & CE & 0.65 & 0.14 & $0.37-1.15$ \\
\hline & LC & Empty & & \\
\hline \multirow{5}{*}{ SLVT } & Other & 1.00 & & \\
\hline & LAA & 1.97 & 0.18 & $0.74-5.18$ \\
\hline & CE & 1.88 & 0.17 & $0.75-4.7$ \\
\hline & Undet & 1.57 & 0.67 & $0.56-3.67$ \\
\hline & LC & Empty & & \\
\hline \multirow{5}{*}{ MAC } & Undet & 1.00 & & \\
\hline & CE & 2.08 & 0.18 & $0.7-6.18$ \\
\hline & Other & 1.92 & 0.33 & $0.5-7.29$ \\
\hline & LAA & 1.34 & 0.66 & $0.35-5.07$ \\
\hline & LC & Empty & & \\
\hline
\end{tabular}

Continue...
Table 2. Continuation.

\begin{tabular}{lcccc}
\hline DWI pattern & Etiology & OR & p-value & $95 \% \mathrm{Cl}$ \\
\hline \multirow{4}{*}{ MPC } & CE & 1.00 & & \\
& Other & 3.61 & 0.004 & $1.5-8.7$ \\
& Undet & 3.61 & 0.004 & $1.5-8.7$ \\
& LAA & 3.52 & 0.003 & $1.54-8.03$ \\
& LC & Empty & & \\
MBAC & LC & 1.00 & & \\
& Other & 9.25 & $<0.001$ & $1.12-76.2$ \\
& Undet & 7.15 & 0.059 & $0.92-55.2$ \\
& CE & 6.75 & 0.068 & $0.86-52.4$ \\
& LC & 2.68 & 0.39 & $0.27-26$ \\
& LAA & 1.00 & & \\
MAP & Other & 5.54 & 0.001 & $1.94-15.1$ \\
& CE & 4.30 & 0.003 & $1.64-11.2$ \\
& Undet & 3.32 & 0.016 & $1.25-8.8$ \\
& LC & Empty & & \\
\hline
\end{tabular}

DWI: diffusion-weighted imaging; OR: Odds Ratio; 95\%Cl: 95\% confidence interval; LAA: large artery- atherosclerosis; LC: lacunar stroke; CE: cardioembolism; Other: stroke of other determined cause; Undet: Stroke of an undetermined cause, because the stroke was cryptogenic, 2 or more causes were identified, or there was an incomplete evaluation; SSCL: scattered lesions in one vascular territory of less than $15 \mathrm{~mm}$; SLVT: scattered lesions in one vascular territory and confluent lesions of $15 \mathrm{~mm}$ or above; MAC: Multiple lesions in multiple vascular territories of unilateral anterior circulation; MPC: multiple lesions in the posterior circulation; MBAC: multiple bilateral lesions on anterior circulation; MAP: multiple lesions in both anterior and posterior circulation.

(OR 4.22; 95\%CI 2.61-6.8), MPC (OR 3.52; 95\%CI 1.54-8.03), and with subcortical lesions of less than $20 \mathrm{~mm}$ (OR 3.47; 95\%CI 1.76-6.85).

Cardioembolic strokes (CE) were associated with cortico-subcortical lesions (OR 3.24; 95\%CI 1.9-5.5), multiple lesions in the anterior and posterior vascular territories (OR 4.3; 95\%CI 1.64-11.2) and with negative DWI results (OR 2.46; 95\% CI 1.1-5.49).

Cryptogenic strokes (only $4.46 \%$ of total number of cryptogenic cases had incomplete etiological evaluation) were associated with normal negative DWI results (OR 4.1; 95\%CI 1.84-8.69), cortical lesions (OR 3.3; 95\%CI 1.25-8.8), subcortical strokes with a diameter $\geq 20 \mathrm{~mm}$ (OR 2.44; 95\%CI 1.045.73), multiple lesions in the anterior and posterior vascular territories (OR 3.33; 95\%CI 1.25-8.81) and finally with cortico-subcortical strokes (OR 2.01; 95\%CI 1.1-3.52).

Lacunar strokes (LC) correlated with a subcortical lesion with diameter $<20 \mathrm{~mm}$ (OR 42.9; 95\%CI 22.7-81.1) and only negative DWI patterns (OR 8.87; 95\%CI 4.03-19.52).

Finally, other etiologies correlated with multiple lesions in the anterior and posterior vascular territories (OR 5.54; 95\%CI 1.94-15.1), MBAC (OR 9.25; 95\%CI 1.12-76.2) and MPC (OR 3.61; 95\%CI 1.5-8.7). 


\section{DISCUSSION}

In this study we found an association between DWI lesion patterns and the TOAST causative classification; these have been previously described by some authors, but their studies included a limited number of patients ${ }^{12,13}$, they were mainly retrospective, and did not include negative or normal DWI results ${ }^{10,11}$, which are very frequent in the $\mathrm{ER}^{4,5}$ especially in patients with low NIHSS ${ }^{14}$.

LAA strokes were associated with scattered lesions in one vascular territory, with small scatter distribution. This finding has been demonstrated in other studies ${ }^{10-12}$ and considered highly suggestive for this etiology ${ }^{12}$.

MPC pattern was also associated with LAA strokes, a pattern that could be explained by a single atherosclerotic lesion in one of the vertebral arteries which could originate emboli to multiple arteries, including the basilar, cerebellar bilateral branches, and posterior cerebral arteries, causing multiple stroke lesions in the posterior circulation ${ }^{15}$.

LAA could also present as subcortical DWI lesions with diameter $<20 \mathrm{~mm}$, a finding not described previously. However, Lee et al. ${ }^{16}$ found that in their experience more than $53 \%$ of atherosclerotic middle cerebral artery lesions were clinically manifested as lacunar strokes and $30 \%$ or more had a small, deep subcortical lesion on DWI; the reasons for these lesions is the probable occlusion of a deep perforator lenticular artery by an atherosclerotic plaque in a mayor intracranial artery.

CE strokes were associated with lesions in multiple anterior and posterior arterial territories and cortico-subcortical lesions as described before ${ }^{6,10,11}$. We also found CE to be associated with negative DWI results; this is probably related to the fact that in our cohort patients with CE arrived earlier to the ER $(\mathrm{p}<0.001)$, probably because of the more dramatic symptoms (NIHSS was higher than in other etiologies, $\mathrm{p}<0.001)$. Early arrival to the ER is one of the factors that are critical for the negative DWI studies ${ }^{4}$.

Strokes of undetermined etiologies were associated with negative DWI, a finding described previously ${ }^{4}$. We could not rule out that some of our cryptogenic AIS were stroke mimic, but in this group of cryptogenic strokes, 19 patients $(15.5 \%)$ had a intracranial arterial occlusion in the symptomatic territory, $52(36.6 \%)$ patients had a stroke detected in the follow-up imaging, and $3(2.1 \%)$ had perfusion abnormalities when the RAPID program was applied. Additionally, this subtype of stroke etiology was associated with cortico-subcortical lesions, which had been described as typical of CE strokes. This finding could be explained by the inclusion in this group of 21 cases who had two possible etiologies: all of them had atrial fibrillation as well as other possible causes for their AIS. As a consequence, they were classified as AIS of undetermined etiology. Some of these AIS were probably the result of their atrial fibrillation and of their episode of CE. This is a limitation of the
TOAST causative classification. In our study, sub-cortical lesions with a diameter $\geq 20 \mathrm{~mm}$ were associated with AIS of undetermined etiology; a similar result was published by Kang et al. for lesions in these locations but whose size was greater than $15 \mathrm{~mm}^{10}$. Finally strokes of undetermined etiologies were also associated with involvement of multiples territories in the anterior and posterior circulation, a frequent finding in cardio-embolic strokes. This could be explained by the inclusion of patients with covert cardioembolic strokes mainly caused by paroxysmal atrial fibrillation not detected by telemetry and in whom prolonged monitoring has been shown to provide a significant increase in the probability of detecting $\mathrm{AF}^{17}$.

Lacunar strokes correlated with subcortical lesions whose diameter was $<20 \mathrm{~mm}$ and with negative DWI results, a finding previously demonstrated ${ }^{10,11}$. Lacunar strokes had $60 \%$ less chance of abnormal DWI evaluation, probably due to their small size ${ }^{3,4}$.

Finally other etiologies were associated with multiple ischemic lesions in both anterior, MAP, and MBAC circulations. Of the patients with other etiologies, $22(1.9 \%)$ had cancer-associated ischemic strokes and 22 (1.9\%) had coagulopathies associated with the ischemic stroke; both groups of diseases had been shown to produce ischemia in multiple brain arterial territories ${ }^{15,18}$.

We can summarize our findings as follows: when there is an AIS with negative DWI the most likely etiology is cryptogenic and lacunar, unless, the patient has a high NIHSS in which case CE embolism could be the cause. Scattered lesions in one vascular territory should rise suspicion for LAA disease. Cortico-subcortical lesions are associated to CE etiology, as it is also the presence of multiple lesions in the anterior and posterior vascular territories. In this last group, cancer and coagulopathies could also be the etiology of this stroke. Finally, cryptogenic strokes can present with multiple DWI patterns.

Our study has several strengths: it included a large number of consecutive patients evaluated early in their evolution with DWI, with frequent addition of thin coronal sections for those cases with negative DWI, and with a few patients (less than 5\%) with incomplete etiological studies.

Our study also has several important limitations, the main one is that it is a single-center experience in which we cannot rule out that some cases with negative DWI evaluations could correspond to stroke mimics. Also, DWI evaluations were performed on MRI with different field strength, which can influence the accuracy of DWI imaging. We also could not rule out the influence of the attending neurologist on the TOAST classification based on the DWI imaging. Furthermore, we did not study inter-observer agreement on the interpretation of DWI, and finally some DWI patterns could be associated with multiple etiologies. In conclusion we found an association between stroke subtypes by TOAST and the DWI lesion patterns. 
1. Kolominsky-Rabas PL, Weber M, Gefeller O, Neundoerfer B, Heuschmann PU. Epidemiology of ischemic stroke subtypes according to TOAST criteria: incidence, recurrence, and longterm survival in ischemic stroke subtypes: a population based study. Stroke. 2001 Dec;32(12):2735-40. https://doi.org/10.1161/ hs1201.100209

2. Adams HP Jr, Bendixen BH, Kappelle LJ, Biller J, Love BB, Gordon DL, et al. Classification of subtype of acute ischemic stroke: definitions for use in a multicenter clinical trial. TOAST. Trial of Org 10172 in Acute Stroke Treatment. Stroke. 1993 Jan;24(1):35-41. https://doi. org/10.1161/01.str.24.1.35

3. Brunser AM, Hoppe A, Illanes S, Díaz V, Muñoz P, Cárcamo D, et al. Accuracy of diffusion-weighted imaging in the diagnosis of stroke in patients with suspected cerebral infarct. Stroke. 2013 Apr;44(4):1169-71. https://doi.org/10.1161/STROKEAHA.111.000527

4. Brunser AM, Cavada G, Venturelli PM, Olavarría V, Rojo A, Almeida J, et al. Diffusion-weighted imaging determinants for acute ischemic stroke diagnosis in the emergency room. Neuroradiology. 2018 Jul;60(7):687-92. https://doi.org/10.1007/s00234-018-2029-x

5. Baird AE, Lövblad KO, Schlaug G, Edelman RR, Warach S. Multiple acute stroke syndrome: marker of embolic disease? Neurology. 2000 Feb;54(3):674-8. https://doi.org/10.1212/wnl.54.3.674

6. Roh JK, Kang DW, Lee SH, Yoon BW, Chang KH. Significance of acute multiple brain infarction on diffusion-weighted imaging. Stroke. 2000 Mar;31(3):688-94. https://doi. org/10.1161/01.str.31.3.688

7. Ay H, Oliveira-Filho J, Buonanno FS, Ezzeddine M, Schaefer PW, Rordorf G, et al. Diffusion-weighted imaging identifies a subset of lacunar infarction associated with embolic source. Stroke. 1999 Dec;30(12):2644-50. https://doi.org/10.1161/01.str.30.12.2644

8. Chaves CJ, Silver B, Schlaug G, Dashe J, Caplan LR, Warach S. Diffusion- and perfusion-weighted MRI patterns in borderzone infarcts. Stroke. 2000 May;31(5):1090-6. https://doi.org/10.1161/01. str.31.5.1090

9. Szabo K, Kern R, Gass A, Hirsch J, Hennerici M. Acute stroke patterns in patients with internal carotid artery disease: a diffusion-weighted magnetic resonance imaging study. Stroke. 2001 Jun;32(6):1323-9. https://doi.org/10.1161/01.str.32.6.1323
10. Kang DW, Chu K, Ko SB, Kwon SJ, Yoon BW, Roh JK. Lesion patterns and mechanism of ischemia in internal carotid artery disease: a diffusion-weighted imaging study. Arch Neurol. 2002 Oct;59(10):1577-82. https://doi.org/10.1001/archneur.59.10.1577

11. Wessels T, Wessels C, Ellsiepen A, Reuter I, Trittmacher S, Stolz E, et al. Contribution of diffusion-weighted imaging in determination of stroke etiology. AJNR Am J Neuroradiol. 2006 Jan;27(1):35-9.

12. Turtzo LC, Gottesman RF, Llinas RH. Diffusion-weighted imaging showing 'pearls' predicts large-vessel disease as stroke etiology. Cerebrovasc Dis. 2009 Jun;28(1):49-54. https://doi. org/10.1159/000219297

13. Koennecke HC, Bernarding J, Braun J, Faulstich A, Hofmeister C, Nohr R, et al Scattered brain infarct pattern on diffusion-weighted magnetic resonance imaging in patients with acute ischemic stroke. Cerebrovasc Dis. 2001 Apr;11(3):157-63. https://doi. org/10.1159/000047632

14. Makin SD, Doubal FN, Dennis MS, Wardlaw JM. Clinically confirmed stroke with negative diffusion-weighted imaging magnetic resonance imaging: longitudinal study of clinical outcomes, stroke recurrence, and systematic review. Stroke. 2015 Nov;46(11):3142-8. https://doi.org/10.1161/STROKEAHA.115.010665

15. Caplan L, Wityk R, Pazdera L, Chang HM, Pessin MS, Dewitt LD. New England Medical Center Posterior Circulation Stroke Registry II. Vascular Lesions. J Clin Neurol. 2005 Apr;1(1):31-49. https://doi. org/10.3988/jcn.2005.1.1.31

16. Lee PH, Oh SH, Bang OY, Joo SY, Joo IS, Huh K. Infarct patterns in atherosclerotic middle cerebral artery versus internal carotid artery disease. Neurology. 2004 Apr;62(8):1291-6. https://doi. org/10.1212/01.wnl.0000120761.57793.28

17. Sanna T, Diener HC, Passman RS, Di Lazzaro V, Bernstein RA, Morillo CA, et al CRYSTAL AF Investigators. Cryptogenic stroke and underlying atrial fibrillation. N Engl J Med. 2014 Jun 26;370(26):2478-86. https://doi.org/10.1056/NEJMoa1313600

18. Singhal AB, Topcuoglu MA, Buonanno FS. Acute ischemic stroke patterns in infective and nonbacterial thrombotic endocarditis: A diffusion-weighted magnetic resonance imaging study. Stroke. 2002 May;33(5):1267-73. https://doi.org/10.1161/01. str.0000015029.91577.36 